\title{
HEAT TREATMENT OF LOW CARBON HIGH MANGANESE TWIP STEEL
}

\author{
Pavel PODANÝ, Michal DUCHEK, Tomáš STUDECKÝ \\ COMTES FHT a.s., Dobrany, Czech Republic, EU \\ pavel.podany@comtesfht.cz
}

https://doi.org/10.37904/metal.2019.867

\begin{abstract}
TWIP steels are steels with a good combination of strength and plasticity. Their application should be relevant in case of critical parts of car bodies. The paper describes the development of a particular type of high carbon manganese steel with low carbon content from the design of the heat to final evaluation of microstructural and mechanical properties of rolled steel sheets. The heat treatment of cold rolled sheets ensured a high elongation in combination with a good yield and tensile strength together with a favorable phase composition of experimental steel.
\end{abstract}

Keywords: TWIP steels, rolling, mechanical properties

\section{INTRODUCTION}

Steels alloyed with $\mathrm{Mn}, \mathrm{Si}$, and $\mathrm{Al}$ in objectively high concentrations show high strength and plasticity when deformed thanks to the mechanical twinning (TWIP steels) or to martensitic transformation induced by deformation (TRansformation Induced Plastisity - TRIP steels. There is no phase transformation in a TWIP steel during cooling or deformation, but the orientation of part of austenite will change due to mechanical twinning. [1-6]

The different performance of the austenite is to its stacking fault energy credited. SFE changes with the alloy composition and deformation temperature [7]. The martensitic transformation from austenite $(\gamma)$ to $\varepsilon$ martensite and/or $\alpha^{\prime}$ martensite occurs with SFE being typically lower than $20 \mathrm{~mJ} / \mathrm{m}^{2}$, whereas mechanical twinning occurs if the stacking fault energy lies between 15 and $30 \mathrm{~mJ} / \mathrm{m}^{2}[5]$.

Steels with a manganese content lower than $15 \%$ shows martensite, resulting from deformation - TRIP effect. Both phenomena, TWIP and TRIP effects can be $f$ in the steels with ca $20 \%$ of manganes found. The TWIP effect usually occurs for manganese content above $25 \%$. However, the exact deformation-transformation performance depends on the particular chemical composition, i.e. the content of the other elements that affect the SFE. These elements in the TWIP steels are carbon, silicon and aluminium. Martensite transformation thus occurs with high manganese content above $25 \%$, when the carbon content is low (below 0.8). Carbon can suppress a martensitic transformation, but could cause the formation of $\mathrm{M} 3 \mathrm{C}$ carbides and the higher carbon content further limits the possibility of welding these TWIP steels together with standard ferritic steels [8].

High manganese steels with TWIP effect usually reach lower tensile strengths (below $1000 \mathrm{MPa}$ ) and low yield strengths (YS) of about $250 \mathrm{MPa}$ [9]. This paper shows how proper heat treatment (annealing) after cold rolling could increase the YS together with combination of excellent ductility.

\subsection{Experimental material and heat treatment}

Chemical composition of studied steel is in Table 1. The heat was melted and casted in a vacuum induction furnace into a round ingot mould. After cooling, further, ingot was $r$ up to the forging temperature of $1100{ }^{\circ} \mathrm{C}$ reheated. Consequently, in a universal hydraulic press, the ingot into a slab of $280 \times 120 \mathrm{~mm}$ cross-section was forged. After grinding, the annealed strip was in four passes rolled to the final thickness of $1.2 \mathrm{~mm}$ with interoperation annealing at $950{ }^{\circ} \mathrm{C}$. After cold rolling, the sheets were to the annealing in vacuum furnace at $600,650,700$ and $800^{\circ} \mathrm{C}$ for 2 hours with slow cooling subjected. The main goal of this annealing was to induce recrystallization in the cold rolled microstructure and thus increase the plasticity of experimental steel. 
Table 1 Chemical composition of experimental steel

\begin{tabular}{|c|c|c|c|c|c|c|}
\hline \multirow{2}{*}{ Heat nr. } & \multicolumn{7}{|c|}{ Element [wt. \%] } & Ar & Fe \\
\cline { 2 - 8 } & $\mathbf{C}$ & Mn & Si & Al & 0.11 & Bal. \\
\hline V16/90 & 0.11 & 28.32 & 1.36 & 1.29 & 0
\end{tabular}

\subsection{Microstructure analysis}

The specimens were prepared by means of following metallographic techniques - grinding and electrolytic polishing in Struers A2 solution. Microstructures revealed by etching with the Klemm's II colour reagent. [11]. For microstructure detection Zeiss Axio Observer light microscope was used. At room temperature, using a Bruker D8 Discover diffractometer, resp. phase analyser (by X-ray diffraction -XRD) was used. For radiation diffraction, one-dimensional detector was used. A cobalt X-ray source had used. The instrument was equipped with a polycapillary lens focusing the primary X-ray beam into a circular spot with a diameter of $0.5 \mathrm{~mm}$.

\subsection{Mechanical properties}

Tensile tests were according to CSN EN ISO 6892-1: Metallic materials - Tensile testing - part 1: Method of test at room temperature carried out. Samples were from the sheet in longitudinal direction cut. Tensile tests were at electromechanical testing machine Zwick/Roell $250 \mathrm{kN}$ carried out. The deformation was by means of strain gauge extensometer with $25 \mathrm{~mm}$ measuring distance measured. Characteristic dimensions were before and after the test measured. These dimensions were used for the investigation of stress-strain characteristics $\left(R_{p 0,2}, R_{m}, A_{g}, A_{5}\right.$ and $\left.Z\right)$.

\section{RESULTS AND DISCUSSION}

\subsection{Microstructure analysis}

In Figure 1a microstructure of the sheet after cold rolling without any heat treatment can be seen. Since etching with Klemm's II reagent does not attack $\varepsilon$ martensite, it appears white in micrographs. The colour of another phase - $\mathrm{Y}$ (austenite) is usually yellow to brown and could be light blue to dark blue according to the etching grade [10]. Steels with high manganese content above $28 \%$ show the prevalence presence of $Y$ (austenite). Nevertheless, this fact is associated with higher carbon content (usually above $0.8 \%$ ). Lower carbon content affects the value of SFE and this lead to the increasing of $\varepsilon$ martensite volume fraction especially in the deformed conditions of the material after cold rolling. The Figure 1a shows the microstructure of deformed austenite with the presence of $\varepsilon$ martensite (white phase). Figures $1 \mathbf{b}, \mathbf{c}, \mathbf{d}$ and $\mathbf{e}$ shows other states of this steel after different annealing temperatures at $800,700,650$ and $600{ }^{\circ} \mathrm{C}$ for two hours with subsequent slow cooling in the vacuum furnace. It is possible to observe fully recrystallized microstructure in the case of samples annealed at $800{ }^{\circ} \mathrm{C}$ and $700{ }^{\circ} \mathrm{C}$ (Figure $1 \mathrm{~b}$ and c). Partial recrystallization with remaining deformed grains is visible at samples annealed at $650^{\circ} \mathrm{C}$ and $600{ }^{\circ} \mathrm{C}$ (Figures $1 \mathrm{~d}$ and $\mathbf{e}$ ).

The microstructure of the sample annealed at $800{ }^{\circ} \mathrm{C}$ is coarse-grained in comparison to cold rolled state and it shows the grain size $\mathrm{G}=8.5$ (according to ASTM E112). Annealing at lower temperature $700{ }^{\circ} \mathrm{C}$ leads to finer grains (see Figure $1 \mathrm{c}$ )). After annealing at $650^{\circ} \mathrm{C}$ and $600{ }^{\circ} \mathrm{C}$, the recrystallization occurred only partially and not whole microstructure was recrystallized. The influence of the annealing temperature on the grain size of recrystallized grains is summarised in the following Table 2.

Table 2 Grain size of recrystallized grains after different heat treatment

\begin{tabular}{|c|c|c|c|c|}
\hline Annealing temperature $\left[{ }^{\circ} \mathrm{C}\right]$ & $\mathbf{8 0 0}$ & $\mathbf{7 0 0}$ & $\mathbf{6 5 0}$ & $\mathbf{6 0 0}$ \\
\hline Average diameter of grain $[\mu \mathrm{m}]$ & 14.6 & 6.1 & 5.0 & 2.5 \\
\hline Grain size G [ASTM E112] & 8.5 & 11.0 & 11.5 & 14.0 \\
\hline$\%$ of recrystallized microstructure & 100 & 100 & 86 & 33 \\
\hline
\end{tabular}



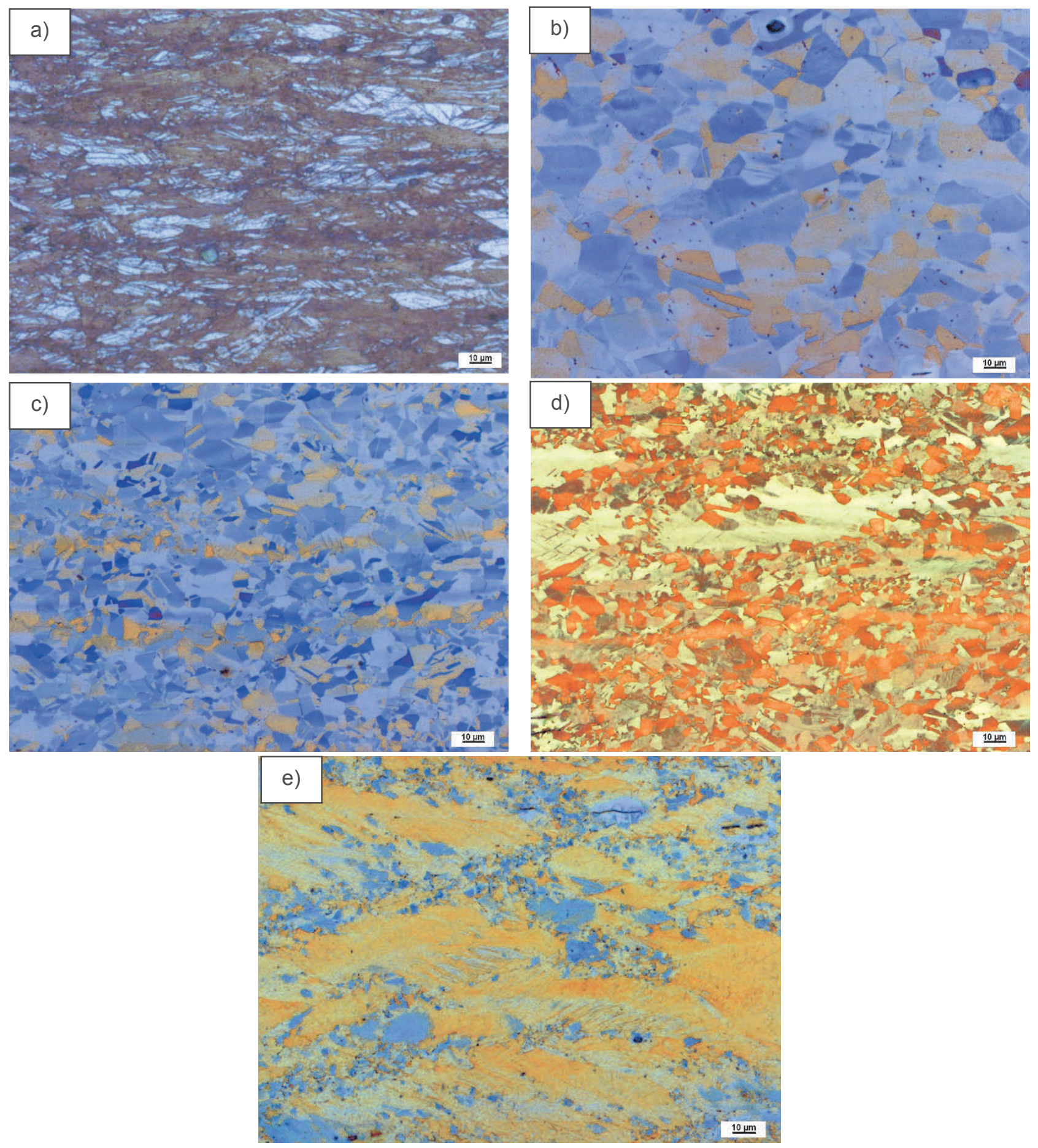

Figure 1 Microstructures of the sheet with thickness $1.2 \mathrm{~mm}$ after: a) cold rolling, b) annealing at $800{ }^{\circ} \mathrm{C} / 2 \mathrm{~h}$, c) annealing at $700{ }^{\circ} \mathrm{C} / 2 \mathrm{~h}, \mathrm{~d}$ ) annealing at $650{ }^{\circ} \mathrm{C} / 2 \mathrm{~h}, \mathrm{e}$ ) annealing at $600{ }^{\circ} \mathrm{C} / 2 \mathrm{~h}$

The phase analysis by $x$-ray diffraction (see Table 3 ) shows that the highest volume fractions of - martensite were obtained on the sheet subjected to the cold rolling without any heat treatment. Annealing leads to the decrease of $\varepsilon$ martensite volume fraction. Nevertheless, the increasing of the temperature of annealing (above $600{ }^{\circ} \mathrm{C}$ ) leads to the increase of $\varepsilon$ martensite volume fraction in comparison to the lower annealing temperatures. The explanation of this behaviour consists in the coarsening of the microstructure. Larger grains could promote the austenite decomposition. In previous studies [6] similar behaviour (in the case of medium manganese TWIP steel) was registered. The XRD did not detect any a (cubic) martensite in the microstructure. 
Table 3 Volume fraction of structural phases according to the X-ray diffraction

\begin{tabular}{|c|c|c|c|c|c|}
\hline \multirow{2}{*}{ Phase [volume \%] } & \multicolumn{5}{|c|}{ Annealing temperature [ ${ }^{\circ} \mathbf{C}$ ] } \\
\cline { 2 - 6 } & Cold rolled & $\mathbf{8 0 0}$ & $\mathbf{7 0 0}$ & $\mathbf{6 5 0}$ & $\mathbf{6 0 0}$ \\
\hline $\mathrm{Y}$ - austenite & 30.8 & 93.1 & 96.5 & 97.0 & 100 \\
\hline$\varepsilon$ - martensite & 69.2 & 6.9 & 3.5 & 3.0 & $\mathrm{X}$ \\
\hline
\end{tabular}

\subsection{Mechanical properties}

The chosen strain rate for standard tensile test was $0.001 \mathrm{~s}-1$. Evaluated mechanical properties $\mathrm{Rp}^{0.2}, \mathrm{Rm}$ and A50 are summarised in Figure 2 a). Figure 2 b) shows the engineering stress-strain curves. These results show that the best combination of tensile properties - TS, YS, and elongation - were reached by means of annealing the cold-rolled sheet from the new TWIP steel at $700{ }^{\circ} \mathrm{C}$ and $650^{\circ} \mathrm{C}$.

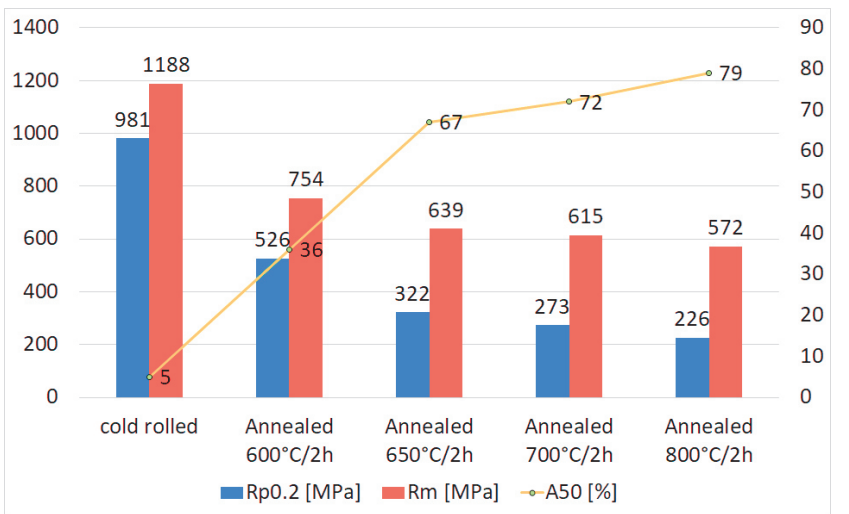

a)

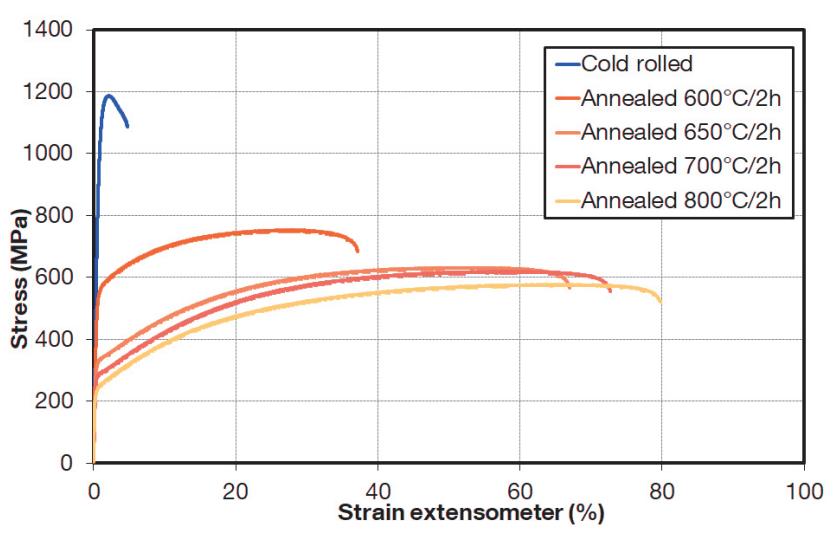

b)

Figure 2 Mechanical properties of experimental high manganese TWIP steel: a) Comparison of mechanical properties of cold rolled and heat treated samples, b) Engineering stress-strain curves

\section{CONCLUSION}

The effect of annealing temperatures on the microstructure, phase composition and mechanical properties of the cold rolled low carbon high-manganese steel was investigated. Experimental steel exhibits the austenitic microstructure with a low austenite content of $\varepsilon$-martensite in annealed state. The best combination of high ductility, good yield strength and tensile strength with a fully recrystallized fine grained austenite microstructure ( $G=11.0$ according to ASTM E 112) was achieved after annealing at $700^{\circ} \mathrm{C}$ for $2 \mathrm{~h}$ with $\mathrm{YS}=273 \mathrm{MPa}$ and a TS $=615 \mathrm{MPa}$. Very good combination of yield strength and tensile strength ( $\mathrm{YS}=322 \mathrm{MPa}$ and TS $=639$ $\mathrm{MPa}$ ) with elongation of $67 \%$ were also achieved for a sample annealed at 650 . However, the microstructure of this sample did not completely recrystallize during annealing.

\section{ACKNOWLEDGEMENTS}

These results were created under the project entitled Development of West-Bohemian Centre of Materials and Metallurgy No.: L01412, financed by the Ministry of Education, Youth and Sports of the Czech Republic.

\section{REFERENCES}

[1] Kim, Y.G., Kim, T.W., Han, J.K. and Chang, R.W. Development of new austenitic Fe-Mn-Al-C steels for automotive applications. Key Eng. Mater. 1993. vol. 84, pp. 461-472. 
[2] Grässel, O., Krüger, L. Frommeyer, G. and Meyer, L.W. High strength Fe-Mn-(Al, Si) TRIP/TWIP steels development-Properties-Application. International Journal of Plasticity. 2000. vol. 16, pp. 1391-1409.

[3] Frommeyer, G. Brüx, U. and Neumann, P. Supra-ductile and high-strength manganese-TRIP/TWIP steels for high energy absorption purposes. ISIJ Int. 2003. vol. 43, pp. 438-446.

[4] Podany, P. Reardon, C. Koukolikova, M., Prochazka, R. and Franc, A. Microstructure, Mechanical Properties and Welding of Low Carbon. Medium Manganese TWIP/TRIP Steel. Metals. 2018. vol. 8, pp. 263-268.

[5] Escobar, D.P., Ferreira de Dafé, S.S. and Santos, D.B. Martensite reversion and texture formation in 17Mn-0.06C TRIP/TWIP steel after hot cold rolling and annealing. Journal of Materials Research and Technology. 2015. vol. 4, no. 2, pp. 162-170.

[6] Podany, P., Dlouhy, J., Koukolikova, M., Martinek, P., Prochazka, R., Kubina, T.and Duchek, M. Phase composition of 15Mn-0.1C-0.4/1.4AI-Si TRIP/TWIP steels after cold rolling and annealing (2016). In ICMAE 2016:7th International Conference on Mechanical and Aerospace Engineering. London: ICMAE, 2016. pp. 121126.

[7] Qin, B. (2007). Crystallography of TWIP Steel, Doctoral dissertation thesis, [viewed 2019-05-07]. Available from: https://www.phase-trans.msm.cam.ac.uk/2007/QinBo Thesis.pdf

[8] Song, S.W., Kwon, Y.J., Lee, T. and Lee, C.S. Effect of Al addition on low-cycle fatigue properties of hydrogen charged high-Mn TWIP steels. Materials Science \& Engineering. 2016. vol. 677A, pp. 421-430.

[9] Dobrzanski, L.A. and Borek, W. Thermo-mechanical treatment of Fe-Mn-(AI,Si) TRIP/TWIP steels. Archives of civil and mechanical engineering. 2012. vol. 12, pp. 299-304.

[10] Vander Voort, G. Metallography. Principles and Practice. New York: McGraw-Hill Book Co., 1999. p. 752. 